\title{
Primary Healthcare Seeking Behaviour of Low-income, Uninsured Patients Across the Public and Private Health Sectors in South Africa
}

\author{
Kerensa Govender ( $\boldsymbol{\nabla}$ kgovender@heroza.org ) \\ Sarah Girdwood \\ Wits Health Consortium Pty Ltd \\ Daniel Letswalo \\ Wits Health Consortium Pty Ltd \\ Lawrence Long \\ Boston University School of Public Health \\ G Meyer-Rath \\ Boston University School of Public Health \\ J Miot \\ Wits Health Consortium Pty Ltd
}

Wits Health Consortium Pty Ltd https://orcid.org/0000-0003-2412-2355

Research article

Keywords: Primary healthcare, private sector, NHI, preferences, utilisation, health care seeking behaviour

Posted Date: October 6th, 2020

DOI: https://doi.org/10.21203/rs.3.rs-74088/v1

License: (c) (1) This work is licensed under a Creative Commons Attribution 4.0 International License. Read Full License 


\section{Abstract}

Background: The proposed National Health Insurance $(\mathrm{NHI})$ system aims to re-engineer primary healthcare (PHC) in South Africa, envisioning both private sector providers and public sector clinics as independent contracting units to the NHI Fund. In 2017, $16 \%$ of the South African population had private medical insurance and predominately utilised private providers. However, it is estimated that up to $28 \%$ of the population access private PHC services, with a meaningful segment of the low-income, uninsured population paying for these services out-of-pocket. The study objective was to characterise the health seeking behaviour of low-income, uninsured patients accessing PHC services in both the public and private sectors, patient movement between sectors, and factors influencing their facility choice.

Methods: We conducted once-off patient interviews on a random sample of 153 patients at 7 private PHC providers (primarily providing services to the low-income uninsured patient population) and their matched public PHC clinic (7 facilities).

Results: The majority of participants were economically active (96/153, 63\%), 139/153 (91\%) did not have health insurance, and $104 / 153(68 \%)$ earned up to $\$ 621 /$ month. A multiple response question found affordability $(67 \%)$ and convenience $(60 \%)$ were ranked as the most important reasons for choosing to usually access care at public clinics $(48 \%)$; whilst convenience $(71 \%)$ and quality of care $(59 \%)$ were key reasons for choosing the private sector $(32 \%)$. There is movement between sectors: $23 / 76(30 \%)$ of those interviewed at a private facility and $8 / 77(10 \%)$ of those interviewed at a public facility indicated usually accessing PHC services at a mix of private and public facilities. Results indicate cycling between the private and public sectors with different factors influencing facility choice.

Conclusions: It is imperative to understand the potential impact on where PHC services are accessed once affordability is mitigated through the $\mathrm{NHI}$ as this has implications on planning and contracting of services under the $\mathrm{NHI}$.

\section{Background}

National health insurance $(\mathrm{NHI})$ has emerged as a key component of existing health financing reforms in middle and low income countries and is critical to the attainment of universal health coverage (UHC) (1). In South Africa the constitution guarantees healthcare access for all, however inequalities still exist with regards to the burden of both communicable and non-communicable disease (2) as well as health access and funding distributions: almost $50 \%$ of total health expenditure is spent on $16 \%$ of the population covered by private medical insurance schemes whilst the other $50 \%$ is spent on $84 \%$ of the population covered by the public sector (3). To address these inequities, the South African Government is currently implementing a NHI scheme which will fund access for all to private and public primary healthcare (PHC) facilities from a combined resource pool, thus facilitating access to quality health services while mitigating the financial burden on individuals and their families (3). The proposed NHI therefore aims to re-engineer primary healthcare, envisioning both private sector providers and public sector clinics to act as independent contracting units to the $\mathrm{NHI}$ Fund (3).

Apart from the effect of reducing financial barriers associated with the cost of accessing health services, the availability of health insurance also impacts health care seeking behaviour by influencing whether, when and 
from where care is sought (4). In recent years, a number of private organisations in South Africa have established innovative models of PHC delivery that aim to provide access to good quality PHC services at affordable rates to underserved populations. It is estimated that $28 \%$ of South African households' made use of the private sector as their primary access point to health care in 2016 (5). In particular, it was estimated in 2006 that of those who are uninsured and with a household income less than $\$ 414$ a month, approximately $22.4 \%$ of their most recent outpatient visits were to private general practitioners (GPs) (6).

Understanding health seeking behaviour and service utilization within the public and private sector has important implications for planning and contracting of services under the NHI. A recent South African study found socio-demographic and economic factors such as age, sex, education, employment and income to have a possible influence on health-care utilization (2). Another study found that utilization is predicted by gender, perceived financial situation, mental and physical health, extra-household resources and the price of a private consultation while the number of visits is predicted by age, physical and mental health, extra-household resources and private provider quality(7). There are however a limited number of studies on this topic and information gaps persist around health access, utilization rates and out of pocket payments in the general South African population(2) (8). There are also very few studies which comprehensively investigate health seeking behaviour exclusively from the patient perspective (9). It is against this background that our study intended to provide a comprehensive description of healthcare seeking behaviour and service utilization, from the patient perspective, within the low-income uninsured population accessing PHC services in either the public, private or a mix of both sectors. This study forms part of a larger analysis to assess the cost and outcomes of models of private $\mathrm{PHC}$ providers targeting this population relative to $\mathrm{PHC}$ service delivery at public sector clinics in South Africa.

\section{Methods}

\section{Sampling}

The population for this study included all patients, aged 18 years and older (adults), who presented for PHC services at seven selected private PHC organisations (primarily providing services to the low-income uninsured patient population) and their matched public sector PHC clinic counterpart (seven facilities) between May 2018 and January 2019, as previously described (10). Only patients able to communicate in English, willing to provide written informed consent, and be physically present for an interview during our site visit were eligible for inclusion in the final random study sample. To achieve a representative sample with a confidence interval of $10 \%$, an alpha error rate of 0.05 and power of $80 \%$ we aimed to conduct a total of 11 interviews per facility (total 14 - seven private and seven public) resulting in a required sample size of 154 . Participants were randomly selected through a systematic random sampling technique. Both the sampling framework and sampling interval used in this study were informed by expected daily volumes, as obtained through a discussion with relevant facility personnel.

\section{Data collection}

This study was approved by the Human Research Ethics Committee of the University of Witwatersrand (ref. no. M171082) and the Institutional Review Board of the Boston Medical Centre (ref. no. H-37230). The study 
design was cross-sectional with data collected during once-off patient interviews. Face-to-face interviews were conducted with enrolled participants and an interviewer administered a semi-structured questionnaire.

Interviews were conducted in a private room within the clinic to ensure confidentiality. Study data were collected and managed using the Research Electronic Data Capture (REDCap) tool; REDCap is a secure, webbased software platform designed to support data capture for research studies (11). Patient interviews took place between May 2018 and January 2019. The interview guide was informed by the Quality of Life Survey (QoL) which is conducted and published by the Gauteng City- Region Observatory (GCRO)(12). Data was collected on demographic characteristics, socio-economic indicators, the associated costs of accessing PHC over the last 12 months, healthcare services utilised over the last year, specifics around any chronic (HIV, TB, diabetes and hypertension) health care requirements over the last year, and patient satisfaction with the care that they have received.

\section{Analysis}

The selection of demographic, socio-economic and health related variables for this analysis was informed by the behavioural model for health service utilisation (13). This model describes health service utilization as being conditional on three sets of factors: predisposing (demographic and social) factors, enabling (economic) factors, and need (health outcome) factors(14). The outcome variable for this analysis was the PHC at which the participant indicated usually accessing care (public PHC, private PHC or mix of public and private facilities). Descriptive statistics were used to provide a summary of the study population across the usual PHC options. A chi-squared test was used to provide a crude test of associations between the PHC facility where care was usually accessed and the demographic, socio-economic and health related variables of our study population.

The influence of socio-economic status (SES) on choice of usual PHC was examined through the creation of an SES index, constructed from household and individual level data using principal component analysis(15). Patients were then stratified into 3 equal sized groups, according to their SES level (low, medium and high) to identify any association between where care was usually accessed and SES level. All statistical data analysis was performed using Stata Statistical Software (Release 15. College Station, TX: StataCorp LLC). Costs are reported in 2019 USD.

\section{Results}

\section{Sample characteristics}

We enrolled and interviewed 153 participants across seven public and seven private PHC facilities - an average of 11 per study site. There was a shortfall of one participant at one study site. Table 1 shows the demographic, socio-economic and health related characteristics of our study sample. Two thirds (67\%) of our study sample were female; the mean age was 40 . The majority of our study population were economically active $(63 \%)$, had no health insurance (91\%) and earned up to $\$ 621$ per month (68\%). Almost two thirds (64\%) reported having an educational level between Grade 8-12 (secondary/high school), 27\% had completed their secondary/ high school education, while $3 \%$ had no formal education. The mean total household income reported was $\$ 453$ per month with a mean household size of 4 people. 
Table 1

Demographic, socio-economic and health related characteristics of respondents, $N=153$

$\begin{array}{ll}\text { Characteristics } & \mathrm{N}(\%)\end{array}$

Gender, $n(\%)$

Male

$51(33)$

Female

$102(67)$

Age (mean, SE)

$40(1.05)$

Relationship status, $n$ (\%)

Married

Unmarried

$110(72)$

Education, $n(\%)$

No Education

4 (3)

Some primary education (Grade (GR) R - GR 6)

15 (10)

Completed primary education (GR 7)

8 (5)

Some secondary education (GR 8-GR11)

$56(37)$

Completed secondary education (Gr12/matric)

$41(27)$

Certificate/diploma from college/technical college /university

23 (15)

Undergraduate from college/ technical college / university

$6(4)$

Health insurance, $n(\%)$

No

$139(91)$

Yes

$14(9)$

Monthly income, $n$ (\%)

$\leq \$ 69$

18 (12)

$\$ 69.01$ - \$207

34 (22)

$\$ 207.01$ - \$414

36 (24)

$\$ 414.01-\$ 621$

16 (10)

$\$ 621.01$ - \$828

4 (3)

$\$ 828.01$ - \$1379

4 (3)

a 65 participants were excluded from this calculation as they either reported a household income of 0 , or refused to respond; standard error of the mean is not reported as this was a categorical variable.

${ }^{b}$ A participant was classified as economically active if they reported working in either the formal sector, informal sector or being self-employed. 


\begin{tabular}{|c|c|}
\hline Characteristics & $N(\%)$ \\
\hline \$1379.01 - \$1724 & $2(2)$ \\
\hline$>$ > 1724 & $1(1)$ \\
\hline Refused to specify/did not know & $38(25)$ \\
\hline Mean household income ${ }^{\text {a }}$ (USD) & $\$ 453$ \\
\hline Household size (Mean, SE) & $4(0.18)$ \\
\hline \multicolumn{2}{|l|}{ Economically active ${ }^{\mathrm{b}}, n(\%)$} \\
\hline No & $57(37)$ \\
\hline Yes & $96(63)$ \\
\hline \multicolumn{2}{|l|}{ Socio-economic status group, $n(\%)$} \\
\hline 1 - low SES & $51(33)$ \\
\hline 2 - medium SES & $51(33)$ \\
\hline 3 - high SES & $51(33)$ \\
\hline \multicolumn{2}{|c|}{ Chronic disease (HIV, diabetes, hypertension), $n$ (\%) } \\
\hline No & $65(42)$ \\
\hline Yes & $88(58)$ \\
\hline \multicolumn{2}{|c|}{$\begin{array}{l}\text { a } 65 \text { participants were excluded from this calculation as they either reported a household income of } 0,0 \\
\text { refused to respond; standard error of the mean is not reported as this was a categorical variable. }\end{array}$} \\
\hline
\end{tabular}

When asked about the health sector where they usually accessed care, 73 (48\%) indicated usually visiting a public health facility, $49(32 \%)$ usually chose a private health facility and $31(20 \%)$ frequently utilised a mix of both facility types (Table 2). Education, health insurance, monthly income and SES were significantly associated with usual PHC choice $(p \leq 0.05)$. 
Table 2

Demographic, socio-economic and health related characteristics of the study population by usual PHC choice Characteristic

PHC usually accessed (usual PHC)

p-

value $^{\mathrm{a}}$

\begin{tabular}{|c|c|c|c|c|c|}
\hline \multicolumn{2}{|c|}{$\begin{array}{l}\text { Public sector [N } \\
=73]\end{array}$} & \multicolumn{2}{|c|}{$\begin{array}{l}\text { Private sector } \\
{[N=49]}\end{array}$} & \multicolumn{2}{|c|}{$\begin{array}{l}\text { Mix of both sectors } \\
{[N=31]}\end{array}$} \\
\hline $\mathbf{N}(\%$ & $\begin{array}{l}95 \% \\
\mathrm{Cl}\end{array}$ & $\mathbf{N}(\%)$ & $\begin{array}{l}95 \% \\
\mathrm{Cl}\end{array}$ & $\mathrm{N}(\%)$ & 95 \\
\hline
\end{tabular}

Gender

Male

$\begin{array}{ll}20(27) \quad 18- \\ & 39\end{array}$

22

$(45)$

$32-$

$9(29)$

16-47

Female

53 (73) $\quad 61-$

82

27

(55)

$41-$

$22(71)$

53-84

Age (mean, SE)

$\begin{array}{ll}39(1.6) & 35- \\ & 42\end{array}$

$\begin{array}{ll}42(2) & 38- \\ & 46\end{array}$

$40(1.8)$

$36-43$

Relationship status

Married

Unmarried

$\begin{array}{ll}15(21) & 13- \\ & 31\end{array}$

16

(33)

21-

47

$12(39)$

23-57

$58(79) \quad \begin{array}{r}69 \\ 87\end{array}$
-8

33
$(67)$

$53-$
79

$19(61)$

43-77

Education

No Education

$3(4)$

GR R - GR 6

7 (10) 5-19

1 (2)

0.3

13

0.11

( $R$

GR 7

5 (7) $\quad 3-16$

4 (8)

3-

$4(13)$

$0(0)$

0.12

GR 7

GR8-GR11

23 (32) $\quad 22-$

2 (4)

$1-$

1 (3)

$0.4-20$

Gr12/matric

$\begin{array}{ll}27(37) & 26- \\ & 49\end{array}$

17
$(35)$

$23-$

$16(52)$

$34-68$

a $\mathrm{p}$-value for a $\mathrm{X}^{2}$ test of association between the specified population characteristic and usual PHC choice

${ }^{b}$ The chi squared test on the monthly income variable did not include the 38 participants who refused to provide an income

c 65 participants were excluded from this calculation ( 40 from the public sector, 20 for the private sector and 5 from those accessing a facility mix) as they either reported a household income of 0 , or refused to respond; standard error of the mean is not reported as this was a categorical variable

${ }^{d}$ A participant was classified as economically active if they reported working in the formal/informal sector or being self-employed 


\begin{tabular}{|c|c|c|c|c|c|c|c|}
\hline \multirow{2}{*}{$\begin{array}{l}\text { Characteristic } \\
\text { Certificate/diploma }\end{array}$} & \multicolumn{6}{|c|}{ PHC usually accessed (usual PHC) } & \multirow{2}{*}{$\begin{array}{l}\text { p- } \\
\text { value }^{a}\end{array}$} \\
\hline & $8(11)$ & $6-21$ & $\begin{array}{l}10 \\
(20)\end{array}$ & $\begin{array}{l}11- \\
34\end{array}$ & $5(16)$ & $7-34$ & \\
\hline Undergraduate & $0(0)$ & & $6(12)$ & $\begin{array}{l}6- \\
25\end{array}$ & $0(0)$ & & \\
\hline Health insurance & & & & & & & 0.002 \\
\hline No & $72(99)$ & $\begin{array}{l}91- \\
100\end{array}$ & $\begin{array}{l}39 \\
(80)\end{array}$ & $\begin{array}{l}66- \\
89\end{array}$ & $28(90)$ & $74-97$ & \\
\hline Yes & $1(1)$ & $0.2-9$ & $\begin{array}{l}10 \\
(20)\end{array}$ & $\begin{array}{l}11- \\
34\end{array}$ & $3(10)$ & $3-26$ & \\
\hline Monthly income ${ }^{b}$ & & & & & & & 0.02 \\
\hline$\leq \$ 69$ & $10(14)$ & $7-24$ & $5(10)$ & $\begin{array}{l}4- \\
22\end{array}$ & $3(10)$ & $3-26$ & \\
\hline$\$ 69.01-\$ 207$ & $18(25)$ & $\begin{array}{l}16- \\
36\end{array}$ & $\begin{array}{l}12 \\
(25)\end{array}$ & $\begin{array}{l}14- \\
38\end{array}$ & $4(13)$ & $5-30$ & \\
\hline$\$ 207.01-\$ 414$ & $13(18)$ & $\begin{array}{l}11- \\
28\end{array}$ & $\begin{array}{l}12 \\
(25)\end{array}$ & $\begin{array}{l}14- \\
38\end{array}$ & $11(36)$ & $21-54$ & \\
\hline$\$ 414.01-\$ 621$ & $7(10)$ & $5-19$ & $2(4)$ & $\begin{array}{l}1- \\
15\end{array}$ & $7(23)$ & $11-41$ & \\
\hline$\$ 621.01-\$ 828$ & $0(0)$ & & $3(6)$ & $\begin{array}{l}2- \\
17\end{array}$ & $1(3)$ & $0.4-20$ & \\
\hline$\$ 828.01-\$ 1379$ & $0(0)$ & & $4(8)$ & $\begin{array}{l}3- \\
20\end{array}$ & $0(0)$ & & \\
\hline$\$ 1379.01-\$ 1724$ & $0(0)$ & & $1(2)$ & $\begin{array}{l}0.3- \\
13\end{array}$ & $1(3)$ & $0.4-20$ & \\
\hline >\$1724 & $0(0)$ & & $0(0)$ & & $1(3)$ & $0.4-20$ & \\
\hline Not specified & $25(34)$ & $\begin{array}{l}24- \\
46\end{array}$ & $\begin{array}{l}10 \\
(20)\end{array}$ & $\begin{array}{l}11- \\
34\end{array}$ & $3(10)$ & $3-26$ & \\
\hline Mean household income $e^{c}$ & $\$ 326$ & & $\$ 570$ & & $\$ 485$ & & \\
\hline
\end{tabular}

a $\mathrm{p}$-value for a $\mathrm{X}^{2}$ test of association between the specified population characteristic and usual $\mathrm{PHC}$ choice

$\mathrm{b}$ The chi squared test on the monthly income variable did not include the 38 participants who refused to provide an income

c 65 participants were excluded from this calculation ( 40 from the public sector, 20 for the private sector and 5 from those accessing a facility mix) as they either reported a household income of 0 , or refused to respond; standard error of the mean is not reported as this was a categorical variable

${ }^{d}$ A participant was classified as economically active if they reported working in the formal/informal sector or being self-employed 


\begin{tabular}{|c|c|c|c|c|c|c|c|}
\hline \multirow{2}{*}{$\begin{array}{l}\text { Characteristic } \\
\text { Household size (Mean, SE) }\end{array}$} & \multicolumn{6}{|c|}{ PHC usually accessed (usual PHC) } & \multirow{2}{*}{$\begin{array}{l}\text { p- } \\
\text { value }^{a}\end{array}$} \\
\hline & \multicolumn{2}{|l|}{$\begin{array}{l}4 \\
(0.29)\end{array}$} & \multicolumn{2}{|l|}{$\begin{array}{l}3 \\
(0.28)\end{array}$} & \multicolumn{2}{|c|}{$4(0.38)$} & \\
\hline \multicolumn{7}{|l|}{ Economically active ${ }^{d}$} & \multirow[t]{3}{*}{0.046} \\
\hline No & $34(47)$ & $\begin{array}{l}35- \\
58\end{array}$ & $12(24)$ & $\begin{array}{l}14- \\
38\end{array}$ & $11(35)$ & $21-54$ & \\
\hline Yes & $39(53)$ & $\begin{array}{l}42- \\
65\end{array}$ & $37(76)$ & $\begin{array}{l}62- \\
86\end{array}$ & $20(65)$ & $46-79$ & \\
\hline \multicolumn{7}{|l|}{ Socio-economic status group } & \multirow[t]{4}{*}{0.02} \\
\hline 1 - low SES & $30(41)$ & $\begin{array}{l}30- \\
53\end{array}$ & $13(27)$ & $\begin{array}{l}16- \\
41\end{array}$ & $8(26)$ & $13-44$ & \\
\hline 2 - medium SES & $28(38)$ & $\begin{array}{l}28- \\
50\end{array}$ & $12(24)$ & $\begin{array}{l}14- \\
38\end{array}$ & $11(35)$ & $21-54$ & \\
\hline 3 - high SES & $15(21)$ & $\begin{array}{l}13- \\
31\end{array}$ & $24(49)$ & $\begin{array}{l}35- \\
63\end{array}$ & $12(39)$ & $23-57$ & \\
\hline \multicolumn{7}{|l|}{$\begin{array}{l}\text { Chronic disease (HIV, diabetes, } \\
\text { hypertension) }\end{array}$} & \multirow[t]{3}{*}{0.56} \\
\hline No & $34(47)$ & $\begin{array}{l}35- \\
58\end{array}$ & $20(41)$ & $\begin{array}{l}28- \\
55\end{array}$ & $11(35)$ & $21-54$ & \\
\hline Yes & $39(53)$ & $\begin{array}{l}42- \\
65\end{array}$ & $29(59)$ & $\begin{array}{l}45- \\
72\end{array}$ & $20(65)$ & $46-79$ & \\
\hline \multicolumn{8}{|c|}{ a $\mathrm{p}$-value for a $\mathrm{X}^{2}$ test of association between the specified population characteristic and usual $\mathrm{PHC}$ choice } \\
\hline \multicolumn{8}{|c|}{$\begin{array}{l}\mathrm{b} \text { The chi squared test on the monthly income variable did not include the } 38 \text { participants who refused to } \\
\text { provide an income }\end{array}$} \\
\hline \multicolumn{8}{|c|}{$\begin{array}{l}\text { c } 65 \text { participants were excluded from this calculation ( } 40 \text { from the public sector, } 20 \text { for the private sector } \\
\text { and } 5 \text { from those accessing a facility mix) as they either reported a household income of } 0 \text {, or refused to } \\
\text { respond; standard error of the mean is not reported as this was a categorical variable }\end{array}$} \\
\hline \multicolumn{8}{|c|}{$\begin{array}{l}\text { d A participant was classified as economically active if they reported working in the formal/informal sector } \\
\text { or being self-employed }\end{array}$} \\
\hline
\end{tabular}

\section{Healthcare seeking behaviour and utilisation}

The majority of participants interviewed at both public and private facilities ( $84 \%$ and $82 \%$, respectively) reported having accessed primary healthcare at that facility prior to enrolment. When asked to indicate the PHC clinic at which they usually access care, participants revealed a tendency to cycle between sectors. Those interviewed in the private sector were three times more likely to use a mix of facility types than participants interviewed in the public sector ( $30 \%$ versus 10\% respectively, Fig. 1). When asked to indicate if they see 
themselves changing the facility where primary healthcare was usually accessed (i.e. public sector to private sector or vice-versa) one participant interviewed in the private sector, usually utilising a mix of facility types, indicated a willingness to switch citing affordability ('It's all affordability') as a driver of this decision.

Healthcare utilisation over 12 months was similar across sectors, with a weighted average number of annual visits of 6.25 for those usually accessing care in the public sector $(N=73), 5.83$ for those usually accessing care in the private sector $(\mathrm{N}=49)$, and 5.81 for those using a mix of facilities $(\mathrm{N}=31)$. An analysis of the utilisation distribution did however reveal a difference across the "Usual PHC" options (Fig. 2). The data showed higher visit frequency (defined as consulting a healthcare provider six or more times a year for this analysis) amongst those usually accessing care in the public sector (58\% in comparison to $45 \%$ amongst those usually choosing to visit the private sector). The majority ( $80 \%)$ of participants with a higher visit frequency in our study sample had been diagnosed with one or more of the chronic conditions of interest in this research (i.e. HIV, diabetes or hypertension). Lower visit frequency (defined as consulting a healthcare provider three or fewer times a year for this analysis) was more likely to be associated with usually accessing care in the private sector (38\% in comparison to $29 \%$ in the public sector). These participants were also less likely to have been diagnosed with one or more of the chronic conditions of interest (38\% reported being diagnosed with either HIV, diabetes, hypertension of a combination of these diseases).

Whilst we interviewed an equal number of patients currently accessing private and public facilities, the type of facility where patients were diagnosed and treated for HIV, TB, diabetes and hypertension differed across sector (Fig. 3).

Equal numbers were diagnosed and treated for hypertension across sectors ( $50 \%$ and $45 \%$ ), whereas more patients are diagnosed $(75 \%)$ and treated $(75 \%)$ for diabetes in the public sector. Despite the greater expense and specialised care required for TB and HIV, a relatively high proportion of TB and HIV patients are treated in the private sector ( $75 \%$ and $42 \%$ respectively). More patients were diagnosed $(71 \%)$ and treated $(75 \%)$ for TB in the private sector, but this is probably driven by the low numbers $(5 / 7$ were diagnosed with TB in the private sector and 3/4 were treated for TB in the private sector) and the inclusion of a specialised TB clinic in the private sector sample.

Patients were asked to list the different healthcare services that they had accessed over the last 12 months and where they access them. They could choose more than one service, e.g. chronic services (related to diabetes, hypertension, HIV, TB, asthma, cancer etc.) and/or acute services (including minor ailments), and/or 'other' services including maternal and child health, sexual and reproductive health services, and support services (eye, oral, palliative etc.) (Table 3). An analysis of all services and facilities accessed by patients over the last 12 months revealed that acute services and chronic care services were the most commonly accessed services (46\% and $43 \%$ ). Public hospitals and private clinics were more likely to be accessed for acute services (64\% and $57 \%$ ), whilst public PHC clinics and private GPs were more likely to be accessed for chronic care services (44\% and $52 \%$ ). Our sample of patients only accessed private hospitals twice in the preceding 12 months: one for acute services and one for maternal and child health services. Public clinics provide the majority of maternal and child health care services (included in the 'Other' category). 
Table 3

All healthcare services accessed over the last 12 months by sector and facility type

\begin{tabular}{|llllll|}
\hline \multicolumn{5}{|c|}{ Service area } \\
\hline Service and facility classification & Chronic care & Acute care & Other & Total \\
\cline { 2 - 6 } & $\mathbf{N}(\%)$ & $\mathbf{N}(\%)$ & $\mathbf{N}(\%)$ & $\mathbf{N}(\%)$ \\
\hline Primary care services & Public clinic & $41(44)$ & $34(36)$ & $19(20)$ & $94(47)$ \\
\cline { 2 - 6 } & Private clinic & $20(43)$ & $27(57)$ & $0(0)$ & $47(24)$ \\
\cline { 2 - 7 } & GP & $14(52)$ & $12(44)$ & $1(4)$ & $27(14)$ \\
\hline Secondary/tertiary services & Public hospital & $10(36)$ & $18(64)$ & $0(0)$ & $28(14)$ \\
\cline { 2 - 7 } & Private hospital & $0(0)$ & $1(50)$ & $1(50)$ & $2(1)$ \\
\hline & & $85(43)$ & $92(46)$ & $21(11)$ & $198(100)$ \\
\hline
\end{tabular}

\section{Drivers of usual PHC facility choice}

Answers to multiple response questions indicated that affordability (67\%) and a convenient location (60\%) were the main reasons for usually accessing care at a public health facility. Those participants who usually accessed care in the private sector specified convenience of location (71\%) and quality of the care received $(59 \%)$ as their main reasons behind facility choice. Finally, participants usually utilising a mix of facilities indicated similar key reasons for visiting each sector type, a convenient location (48\%) and affordability (39\%) were the main drivers of public sector access while quality of care (71\%) and location convenience (42\%) emerged as key drivers of private sector access for this segment of the study population. Refer to Table 4 for more detail. 
Table 4

Reasons for usually using a public or private facility or mix of both (this was a multiple response question)

\begin{tabular}{|c|c|c|c|c|}
\hline \multirow{3}{*}{$\begin{array}{l}\text { PHC usually accessed } \\
\text { (usual PHC) }\end{array}$} & \multicolumn{2}{|c|}{$\begin{array}{l}\text { Reason for usually using } \\
\text { public facilities }\end{array}$} & \multicolumn{2}{|c|}{$\begin{array}{l}\text { Reason for usually using } \\
\text { private facilities }\end{array}$} \\
\hline & $\begin{array}{l}\text { Public Sector } \\
(\mathrm{N}=73)\end{array}$ & $\begin{array}{l}\text { Mix of both } \\
\text { sectors }\end{array}$ & $\begin{array}{l}\text { Private Sector } \\
(N=49)\end{array}$ & $\begin{array}{l}\text { Mix of both } \\
\text { sectors }\end{array}$ \\
\hline & & {$[\mathrm{N}=31]$} & & {$[\mathrm{N}=31]$} \\
\hline & $\mathbf{N}(\%)$ & $\mathbf{N}(\%)$ & $\mathbf{N}(\%)$ & $\mathbf{N}(\%)$ \\
\hline It is affordable & $49(67)$ & $12(39)$ & $10(20)$ & $0(0)$ \\
\hline I receive good quality of care & $9(12)$ & $4(13)$ & $29(59)$ & $22(71)$ \\
\hline It is convenient for me to access & $44(60)$ & $15(48)$ & $35(71)$ & $13(42)$ \\
\hline $\begin{array}{l}\text { There are no private/public health care } \\
\text { facilities close by }\end{array}$ & $0(0)$ & $0(0)$ & $0(0)$ & $0(0)$ \\
\hline I have been before and they could help & $3(4)$ & $4(13)$ & $2(4)$ & $3(10)$ \\
\hline The staff are friendly/helpful & $5(7)$ & $2(6)$ & $7(14)$ & $5(16)$ \\
\hline It has the medicine I need & $12(16)$ & $8(26)$ & $5(10)$ & $9(29)$ \\
\hline Other* & $0(0)$ & $2(6)$ & $2(4)$ & $1(3)$ \\
\hline
\end{tabular}

\section{Patient satisfaction}

All repeat patients to the facility of interview were asked to describe their level of satisfaction with the care received at that clinic: $97 \%$ of private sector clients were either very satisfied or satisfied with the service they received as compared to $74 \%$ in the public sector. The public sector had a higher proportion of patients who were either dissatisfied or indifferent (neither satisfied/ dissatisfied). This was reflected in the open-ended comments patients were asked to provide on their experience of care: $73 \%$ of negative comments (i.e. slow or long waiting times, staff shortages, inadequate opening hours or cramped facilities etc.) were by patients who attended a public sector clinic, whilst $63 \%$ of positive comments on the experience of care (friendly and good staff etc.) were by patients attending a private sector clinic (Table 5). 
Table 5

General comment on experience of care by sector

\begin{tabular}{|lllll|}
\hline \multirow{2}{*}{ Experience of care } & \multicolumn{2}{l}{ Public sector } & Private sector & Total \\
\cline { 3 - 5 } & $\mathbf{N}(\%)$ & $\mathbf{N}(\%)$ & $\mathbf{N}(\%)$ \\
\hline \multirow{2}{*}{ Negative } & Slow/long waiting times & $11(85)$ & $2(15)$ & $13(100)$ \\
\cline { 2 - 5 } & Hours/size* & $3(75)$ & $1(25)$ & $4(100)$ \\
\cline { 2 - 5 } & Other & $6(55)$ & $5(46)$ & $11(100)$ \\
\cline { 2 - 5 } & Staff shortage & $4(80)$ & $1(20)$ & $5(100)$ \\
\hline Positive & Satisfied & $10(37)$ & $17(63)$ & $27(100)$ \\
\cline { 2 - 5 } & Friendly/good staff & $1(17)$ & $5(83)$ & $6(100)$ \\
\cline { 2 - 5 } & Other & $3(60)$ & $2(40)$ & $5(100)$ \\
\hline Total & & $38(54)$ & $33(47)$ & $71100)$ \\
\hline *Includes comments referring to inconvenient opening hours or cramped facilities \\
\hline
\end{tabular}

\section{Discussion}

This study has provided a description of health seeking behaviour amongst the low-income uninsured population who choose to access PHC services at either a public facility, private facility or utilise a mix of facility types in 2 provinces in South Africa. Results indicate a willingness to shift between sectors; this movement is currently most likely constrained by finances and socio-economic status.

The perceived benefits and quality of care reported by participants is likely a strong contributing factor to movement of patients from the public sector to the private sector when health care is deemed urgent or critical and funds make this possible. These findings align with those reported by a previous study which found that patients in Ghana who could afford to go to a private facility were willing to choose these clinics over government facilities covered by the Ghanaian $\mathrm{NHI}$, mostly due to their perception of better quality of care in the private sector (16). Another study looking at private providers operating under $\mathrm{NHI}$ schemes in both Ghana and Kenya found that study participants from both countries expressed an overall preference for accessing care in the private sector, with most citing shorter waiting times and more respectful treatment as the reasons for this; these participants also felt that $\mathrm{NHI}$ coverage not only provided greater access to healthcare, but also allowed them to access higher quality private clinics which they preferred over public sector facilities (17). Similarly a previous South African study found that private health care played an important role in the health care decisions of poor South Africans who indicated a preference for private health care, despite constraints of money and access (18). A discrete choice experiment (DCE) undertaken in the Western and Eastern Cape provinces of South Africa also revealed a preference to not to seek care at a public facility, with the probability of attending public health facilities strongly influenced by attributes related to clinical quality such as the availability of medication (19). Access to additional funds and perceived quality of service from a private provider influence where healthcare is accessed (7). 
Finally the utilization of private for profit health facilities has been shown in previous research to be dependent on factors such as insurance coverage, high education level, and being a formal job holder (20). These findings are consistent with our results which similarly indicate that education, health-insurance, monthly income and socio-economic status are strong predictors of where care is usually accessed. Previous studies in low income countries have also shown that education influenced choice of providers (21)(22). Furthermore, better educated and wealthier participants in a Ghanaian based study were significantly more likely to visit private health facilities compared to public health facilities (22). Importantly, given the context of this current study, controlling for health-insurance was previously found to lessen the influence of factors such as education and occupation (20). Our study reveals that potential impact on volumes could mean that while most high visit frequency patients currently access care in the public sector, a portion of these visits may be distributed to the private sector under $\mathrm{NHI}$ which might result in more than the estimated three annual visits per person per year (23)(24). Further research on a larger sample is needed to confirm the robustness of these findings and to explore the influence of select population characteristics and UHC on health seeking behaviour within this lowincome uninsured population.

This study helps provide a better understanding of healthcare utilisation in South Africa amongst the lowincome uninsured population and shows potential implications on health-seeking behaviour for the implementation of $\mathrm{NHI}$. Its limitations include the small study sample, which limited the power to detect significance, and restricted further regression analysis of predictors. The study also asked for sensitive information such as personal and household income which may be subject to over/under-reporting bias. This is a cross-sectional study therefore causal relations could not be ascertained. Lastly, while data on health seeking behaviour for a 12-month period was obtained during interviews, this could have been subject to recall and response bias.

\section{Conclusions}

The results of our study indicate cycling between the private and public sectors and a willingness to shift between sectors, with patients seeking better quality of care in the private sector although this is currently most likely limited by finances and socio-economic status. With the implementation of $\mathrm{NHI}$ focused on removing financial barriers and enabling access to quality healthcare regardless of socio-economic group, affordability should no longer be a constraint on accessing care outside of the public sector. Understanding the potential impact on healthcare utilisation once affordability is mitigated through the $\mathrm{NHI}$ is important for planning, and has implications for the set-up of contracting systems for services under the NHI.

\section{List Of Abbreviations}

DCE - Discrete choice experiment

$\mathrm{NHI}$ - National health insurance

PHC - Primary healthcare

REDCap - Research Electronic Data Capture

Page 14/19 


\section{Declarations}

\section{Acknowledgements}

We would like to acknowledge the participants in this study who generously gave of their time to interview with us.

\section{Ethics approval and consent to participate}

This study was approved by the Human Research Ethics Committee of the University of Witwatersrand (protocol no. M171082) and the Institutional Review Board of the Boston University Medical Centre (IRB no. H37230). All potential participants were required to provide written informed consent prior to being deemed eligible for enrolment in the study.

\section{Consent for publication}

Not applicable.

\section{Availability of data and materials}

The datasets supporting the conclusions of this article are available upon request via email from the authors.

\section{Competing interests}

JM has received funding from Discovery Fund to conduct research at one of the clinic sites used in this study.

\section{Funding}

This study was made possible by the generous support of the American people through the President's Emergency Plan for AIDS Relief (PEPFAR) through the United States Agency for International Development (USAID) under the terms of Cooperative Agreements AID 674-A-12-00029 and 72067419CA00004 to HE2RO. The contents are the responsibility of the authors and do not necessarily reflect the views of PEPFAR, USAID or the US government. The funders of the study had no role in study design, data collection, data analysis, data interpretation, or writing of the report.

\section{Author contributions}


SG, LL, GM-R, and JM conceived the study. KG, SG and DL developed, setup and conducted patient interviews. KG and SG prepared the data. KG, SG, LL, GM-R, and JM contributed to the interpretation of results. $K G$ and SG wrote the first draft of the manuscript. This and all subsequent drafts were reviewed and revised by all authors. All authors read and approved the final manuscript.

\section{References}

1. Chomi E, Mujinja P, Enemark U, Hansen K, Kiwara A. Health care seeking behaviour and utilisation in a multiple health insurance system: does insurance affiliation matter? Int J Equity Health. 2014;13(25):111.

2. Abaerei A, Ncayiyana J, Levin J. Health-care utilization and associated factors in Gauteng province, South Africa. Glob Health Action [Internet]. 2017;10(01). Available from: https://doi.org/10.1080/16549716.2017.1305765

3. The Department of Health South Africa. National Health Act, 2003; National Health Insurance Policy Whitepaper 2017 [Internet]. 2017. Available from: www.health.gov.za

4. Robyn P, Hill A, Liu Y, Souares A, Savadogo G, Sie A, et al. Econometric analysis to evaluate the effect of community-based health insurance on reducing informal self-care in Burkina Faso. Health Policy Plan. 2012;27(March 2011):156-65.

5. Statistics South Africa. General Household Survey 2016 [Internet]. 2016. Available from: www.statssa.gov.za

6. Broomberg J. Consultative Investigation into Low Income Medical Schemes - Final Report Pretoria: National Department of Health [Internet]. 2006. Available from: https://www.medicalschemes.com/Publications.aspx (accessed 17 July 2018).

7. Skordis-Worrall J, Hanson K, Mills A. Estimating the demand for health services in four poor districts of Cape Town, South Africa. Int Health [Internet]. 2011;3(1):44-9. Available from: http://dx.doi.org/10.1016/j.inhe.2011.01.004

8. Harris B, Goudge J, Ataguba JE, Nxumalo N. Inequities in access to health care in South Africa. J Public Heal Policy Vol [Internet]. 2011;32(S1):S102-S123. Available from:

https://www.researchgate.net/publication/51469049_Inequities_in_access_to_health_care_in_South_Africa

9. Christian C, Burger C, Claassens M, Bond V, Burger R. Patient predictors of health-seeking behaviour for persons coughing for more than two weeks in high-burden tuberculosis communities: the case of the Western Cape, South Africa. BMC Health Serv Res [Internet]. 2019;19(160 (2019)):1-8. Available from: https://doi.org/10.1186/s12913-019-3992-6

10. Girdwood S, Govender K, Long L, Miot J, Meyer-Rath G. Primary healthcare delivery models for uninsured low-income earners during the transition to Universal Health Coverage: Perspectives of private South African providers. (in Press South African Med J [Internet]. 2019;109(10):771-83. Available from: http://www.samj.org.za/index.php/samj/article/view/12730

11. Harris P, Taylor R, Thielke R, Payne J, Gonzalez N, Conde J. Research electronic data capture (REDCap) - A metadata-driven methodology and workflow process for providing translational research informatics support. J Biomed Inf. 2009;42(2):377-81. 
12. Gauteng City Region Observatory. The evolution of the Quality of Life questionnaire [Internet]. Interactive data visualisation. 2018. Available from: https://gcro.ac.za/data-gallery/interactive-datavisualisations/detail/the-evolution-of-the-quality-of-life-questionnaire/

13. Andersen R. Revisiting the Behavioral Model and Access to Medical Care: Does It Matter? J Health Soc Behav. 1995;36(1):1-10.

14. Li Y, Nong D, Wei B, Feng Q, Luo H. The impact of predisposing, enabling, and need factors in utilization of health services among rural residents in Guangxi, China. BMC Health Serv Res [Internet]. 2016;16(1):1-9. Available from: http://dx.doi.org/10.1186/s12913-016-1825-4

15. Vyas S, Kumaranayake L. Constructing socio-economic status indices: How to use principal components analysis. Health Policy Plan. 2006;21(6):459-68.

16. Agyepong I, Abankwah D, Ambroso A, Chun C, Dodoo J, Lee S, et al. The "universal" in UHC and Ghana's National Health Insurance Scheme: Policy and implementation challenges and dilemmas of a lower middle income country. BMC Health Serv Res [Internet]. 2016;16(1). Available from: http://dx.doi.org/10.1186/s12913-016-1758-y

17. Suchman L. Accrediting private providers with National Health Insurance to better serve low-income populations in Kenya and Ghana: A qualitative study. Int J Equity Health. 2018;17(1):1-18.

18. Havemann R, Berg S. The demand for health care in South Africa. J Stud Econ Econom [Internet]. 2002;27. Available from: https://www.researchgate.net/publication/24134202_The_demand_for_health_care_in_South_Africa

19. Honda A, Ryan M, Niekerk R Van, Mcintyre D. Improving the public health sector in South Africa: eliciting public preferences using a discrete choice experiment. Health Policy Plan [Internet]. 2015;30(May 2014):600-11. Available from: https://academic.oup.com/heapol/article/30/5/600/660383

20. Beogo I, Liu C, Chou Y, Chen C, Huang N. Health-Care-Seeking Patterns in the Emerging Private Sector in Burkina Faso: A Population-Based Study of Urban Adult Residents in Ouagadougou. PLoS One. 2015;9(5).

21. Latunji $\mathrm{O}$, Akinyemi $\mathrm{O}$. Factors influencing health-seeking behaviour among civil servants in Ibadan, Nigeria. Ann Ibadan Postgrad Med. 2018;16(1):52-60.

22. Janjua NZ, Khan MI, Usman HR, Azam I. Pattern of health care utilization and determinants of care-seeking from GPs in two districts of Pakistan. South East Asian J Trop Med Public Heal. 2006;37(6):1243-53.

23. Moosa S, Luiz J, Carmichael T, Peersman W, Derese A. Insights of private general practitioners in group practice on the introduction of National Health Insurance in South Africa. African J Prim Heal care Fam Med [Internet]. 2016;8(1):e1-6. Available from: http://www.ncbi.nlm.nih.gov/pubmed/27380785

24. Moosa S, Luiz J, Carmichael T. Introducing a national health insurance system in South Africa: A general practitioner's bottom-up approach to costing. South African Med J. 2012;102(10):794-7.

\section{Figures}


Interviewed at a public sector PHC facility ( $\mathrm{N}=77)$

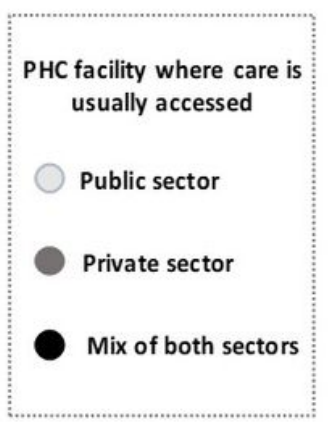

Public sector $69(90 \%)$

\section{Mix of both sectors} $8(10 \%)$

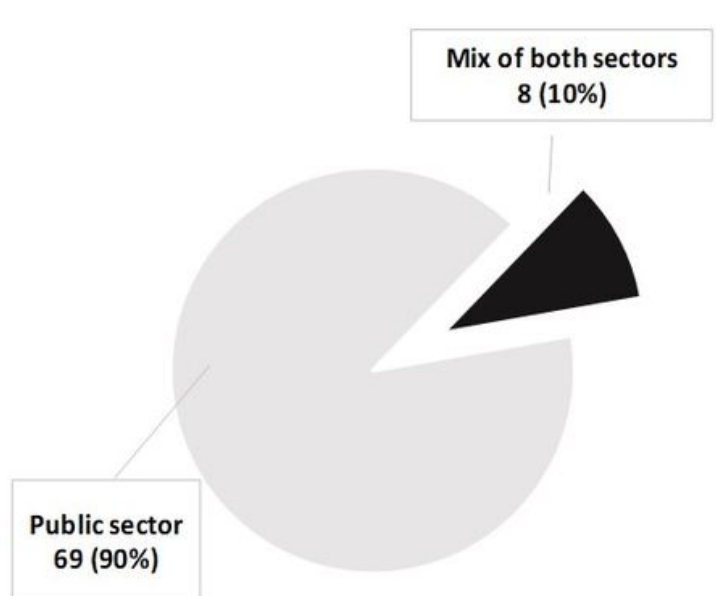

Interviewed at a private

sector PHC facility ( $\mathrm{N}=76$ )

Figure 1

Usual PHC choice relative to the sector where the participant was interviewed

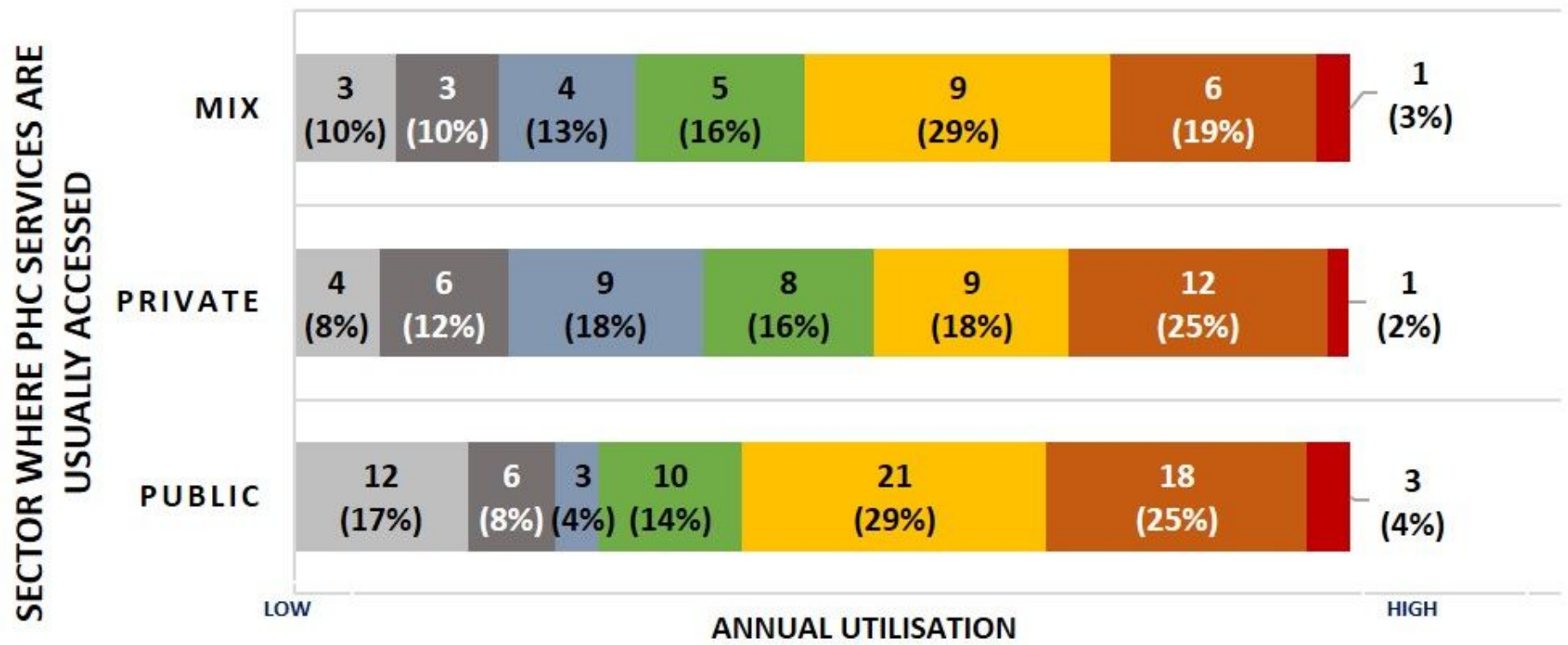

Once a year (1)

Three times a year (3)

Six times a year (6)

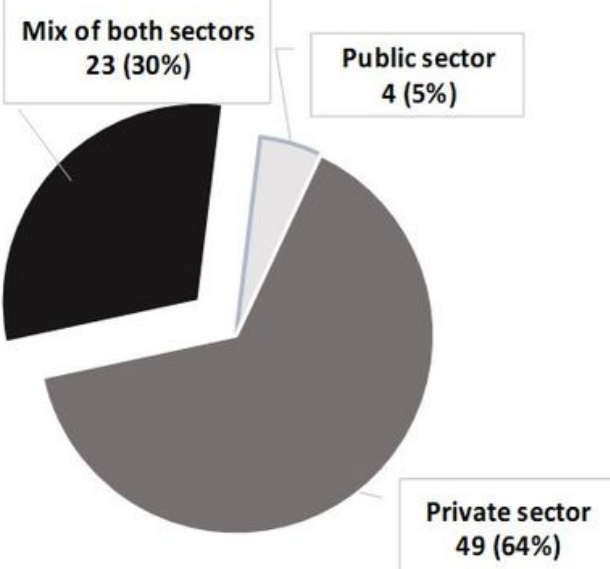



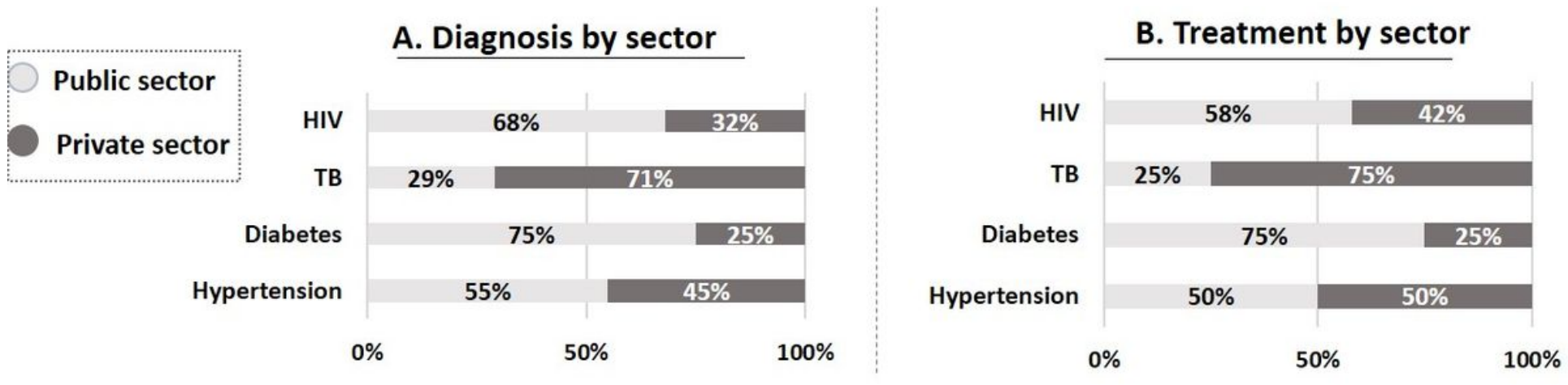

Figure 3

A comparison of diagnosis and treatment by sector 